\title{
Volumetric and Viscometric Study of Interactions of Amino Acids in Aqueous Sucrose Solution at Different Temperatures
}

\author{
PARVINDER KHANUJA \\ Department of Chemistry, S.N.P. G. College, Khandwa (M.P.) India \\ p_khanuja@rediffmail.com
}

Received 14 January 2013 / Accepted 15 February 2013

\begin{abstract}
Density and viscosity measurements were performed for amino acids in 0.05-0.25 M aqueous sucrose at $293.15,303.15$ and $313.15 \mathrm{~K}$. The measured values of density and viscosity in a ternary system were used to determine some important parameters, such as the partial molar volume, the transfer partial molar volume, partial molar volume expansibility, viscosity $B$-coefficient, variation of $B$ with temperature $\mathrm{d} B / \mathrm{d} T$ and free energy of activation. The results were interpreted in terms of solute-solute and solute-solvent interactions and structure making/breaking ability of solutes in aqueous sucrose solution.
\end{abstract}

Keywords: Density, Masson equation, Viscosity, Viscosity $B$-coefficient

\section{Introduction}

Interaction of amino acids in aqueous sucrose solution at different temperature plays an important role to understand biochemical process in living cells. It has been reported earlier that mono and disaccharides are structure makers ${ }^{1-5}$. Hydration shell co-sphere overlap effect depends significantly on the relative position of the $\mathrm{OH}$ group in the carbohydrate molecules. It would be interesting to examine whether the structure modification of water by these sugars get enhanced or suppress in presence of an ion.

Amino acids, particularly important in biochemistry, are critical to life and have many functions in metabolism one particularly important function is to serve as a building blocks of proteins ${ }^{6-8}$. There are extensive volumetric properties studies of amino acid in mixed aqueous solvents such as sodium sulphate, potassium thiocynate, caffeine and glycerol $^{9-12}$ can act as an effective probes of their confirmation in solutions.

In this paper we report density, viscosity \& apparent molar volume $\emptyset_{\mathrm{v}}$ of $(0.05-0.15 \mathrm{~m})$ amino acids (glycine and $L$-alanine) in $(0.05-0.25 \mathrm{~m})$ aqueous sucrose solution at different temperatures as $293.15,303.15$ and $313.15 \mathrm{~K}$ we also reported partial molar volume at infinite dilution, transfer partial molar volume, partial molar expansibilities, Falkenhagen coefficient A, Jones - Dole coefficient B, Free energy parameter of per mole solute and per mole of solvent which are calculated by experimentally measured density and viscosity. 


\section{Experimental}

All the chemicals sucrose, Glycine and $L$ - Alanine were of Analar quality. Freshly distilled water with specific conductance of $\sim 10^{-6} \Omega \mathrm{cm}^{-1}$ was used to preparing solution throughout the experiment. The densities of solutions were measured at $293.15,303.15$ and $313.15 \mathrm{~K}$ using a density bottle made of borosil glass. The mass measurement were done on digital electronic balance(Sartorius GC103).Viscosity determines with calibrated U shaped Ostwald viscometer with sufficiently long reflux time more than $120 \mathrm{~s}$. to avoid kinetic energy correction. An average of triplet measurement was taken in to account. Temperature was controlled by thermostatic water-bath with $\pm 0.1{ }^{0} \mathrm{C}$ accuracy. The viscosities were calculated ${ }^{13-14}$ by using the formula $\eta / \eta_{0=} t d / t_{0} d_{0}$ where $\eta, t \& d$ are the absolute viscosity, time of flow and density of solution, while $\eta_{0}, t_{0} \& d_{0}$ are same quantities for the solvent water. The absolute viscosities of water at $293.15,303.15$ and $313.15 \mathrm{~K}$ were taken as $1.005,0.8007$ and 0.656 centipoise respectively. The densities of water were taken as $0.9982,0.99565$ and $0.9922{\mathrm{~g} . \mathrm{cm}^{-3}}^{-}$respectively ${ }^{13-14}$.

\section{Results and Discussion}

\section{Volumetric study}

The experimental densities, viscosities and apparent molar volumes of amino acids (0.05$0.15 \mathrm{~m})$ in aqueous sucrose $(0.05-0.25 \mathrm{~m})$ were measured at $293.15,303.15$ and $313.15 \mathrm{~K}$. The apparent molar volumes, $\varnothing_{\mathbf{v}}$ of glycine and $L$-alanine are calculated by using the following equation ${ }^{15}$ :

$$
\emptyset_{\mathrm{v}=} \mathrm{M} / \mathrm{d}_{0}-1000\left(\mathrm{~d}-\mathrm{d}_{\mathrm{o}}\right) / \mathrm{d}_{0 \mathrm{C}}
$$

Where $d_{0}$ and $d$ are the densities of solvent and solution respectively, $\mathrm{C}$ is the molar concentration in $\mathrm{g} / \mathrm{L}$ and $M$ is molecular weight of solute. For each system $\emptyset_{\mathbf{v}}$ with $\sqrt{ }_{\mathrm{c}}$ were found to be linear thus the data are fitted to masson ${ }^{16}$ equation, these were used to calculate limiting partial molar volume and experimental slope by least square method.

$$
\emptyset_{\mathrm{v}}=\emptyset_{\mathrm{v} 0}+S v \sqrt{c}
$$

In these $S_{v}$ is the experimental slope or volumetric pair wise interaction coefficient provides information regarding solute-solute interaction. While $\Phi \mathrm{v}_{0}$ provides information regarding solute-solvent interaction. The values of $\Phi v_{0}$ and $S_{v}$ for the amino acids in aqueous sucrose solution at different temperatures are presented in Table 1 and 2. It is found that value of $S_{v}$ is positive for glycine and negative for alanine in aqueous sucrose solution. It can be also observed that in case of glycine $S_{v}$ decrease with increasing temperature and reverse trend observed that in case of alanine.

Table 1. Partial molar volume at infinite dilution $\Phi \mathrm{v}_{0}\left(\mathrm{~cm}^{3} \mathrm{~mol}^{-1}\right)$ of glycine and $L$ - alanine in aqueous sucrose solution at different temperatures $(293.15,303.15$ and $313.15 \mathrm{~K})$

\begin{tabular}{ccccccc}
\hline $\begin{array}{c}\text { Sucrose } \\
\text { Conc. } \mathrm{m}\end{array}$ & $293.15 \mathrm{~K}$ & $303.15 \mathrm{~K}$ & $313.15 \mathrm{~K}$ & $293.15 \mathrm{~K}$ & $303.15 \mathrm{~K}$ & $313.15 \mathrm{~K}$ \\
\hline 0.25 & 42.24 & 43.12 & 44.03 & 59.48 & 60.67 & 61.31 \\
0.20 & 42.18 & 43.05 & 43.96 & 59.44 & 60.63 & 61.29 \\
0.15 & 42.12 & 42.99 & 43.93 & 59.41 & 60.58 & 61.25 \\
0.10 & 42.05 & 42.93 & 43.89 & 59.34 & 60.51 & 61.20 \\
0.05 & 42.01 & 42.89 & 43.85 & 59.27 & 60.45 & 61.16 \\
\hline
\end{tabular}


Table 2. Experimental slope $\mathrm{S}_{\mathrm{v}}\left(\mathrm{cm}^{3} \mathrm{~L}^{1 / 2} \mathrm{~mol}^{-3 / 2}\right)$ of glycine and $L$ - alanine in aqueous sucrose solution at different temperatures $(293.15,303.15$ and $313.15 \mathrm{~K})$

\begin{tabular}{ccccccc}
\hline Sucrose & & Glycine & & & L-Alanine \\
Conc. M & $293.15 \mathrm{~K}$ & $303.15 \mathrm{~K}$ & $313.15 \mathrm{~K}$ & $293.15 \mathrm{~K}$ & $303.15 \mathrm{~K}$ & $313.15 \mathrm{~K}$ \\
\hline 0.25 & 1.12 & 1.09 & 0.47 & -1.29 & -1.19 & -1.12 \\
0.20 & 1.06 & 0.92 & 0.57 & -1.43 & -1.26 & -1.19 \\
0.15 & 0.92 & 0.81 & 0.55 & -1.46 & -1.24 & -1.27 \\
0.10 & 0.9 & 0.72 & 0.54 & -1.76 & -0.95 & -1.4 \\
0.05 & 0.84 & 0.71 & 0.52 & -1.99 & -0.95 & -1.37 \\
\hline
\end{tabular}

The volume of transfer $\Delta \Phi \mathrm{v}_{0 \text { tr }}$ of amino acids from water to aqueous sucrose solution was calculated by using given relation at different temperatures and is summarized in Table 3 . $\Delta \Phi \mathrm{v}_{0 \mathrm{tr}}=\Phi \mathrm{v}_{0}$ (amino acid in aq. Sucrose) $-\Phi \mathrm{v}_{0}$ (amino acid in pure water.)

Table 3. $\Delta \Phi v_{0 \text { tr }}\left(\mathrm{cm}^{3} \mathrm{~mol}^{-1}\right)$ of glycine and $L$-alanine in aqueous sucrose solution at different temperatures $(293.15,303.15$ and $313.15 \mathrm{~K})$

\begin{tabular}{ccccccc}
\hline $\begin{array}{c}\text { Sucrose } \\
\text { Conc. M }\end{array}$ & $293.15 \mathrm{~K}$ & $303.15 \mathrm{~K}$ & $313.15 \mathrm{~K}$ & $293.15 \mathrm{~K}$ & $303.15 \mathrm{~K}$ & $313.15 \mathrm{~K}$ \\
\hline 0.25 & -0.54 & -0.16 & 0.03 & 0.39 & -0.05 & 0.11 \\
0.20 & -0.6 & -0.23 & -0.042 & 0.35 & -0.09 & 0.09 \\
0.15 & -0.66 & -0.29 & -0.07 & 0.32 & -0.14 & 0.05 \\
0.10 & -0.73 & -0.35 & -0.1 & 0.25 & -0.21 & 0.002 \\
0.05 & -0.77 & -0.39 & -0.14 & 0.18 & -0.27 & -0.04 \\
$\Phi \mathrm{v}_{0}$ water & 42.78 & 43.28 & 44.00 & 59.909 & 60.72 & 61.2 \\
\hline
\end{tabular}

It is found that value of $\Delta \Phi \mathrm{v}_{0 \text { tr }}$ is negative for glycine and positive $\Delta \Phi \mathrm{v}_{0 \text { tr }}$ value obtained at for alanine in aqueous sucrose solution. Positive $\Delta \Phi v_{0 \text { tr }}$ changes sign at higher temperature in case of $L$-alanine. In case of glycine it can be found that the negative $\Delta \Phi \mathrm{v}_{0 \text { tr }}$ values are decreasing continuously with increasing concentration of sucrose and temperature. Similar observation has been obtained by Gupta et al. ${ }^{17}$ and Zhuo et al. ${ }^{18}$ in their studies.

The partial molar volume of transfer of amino acids from water to aqueous sucrose solutions can be further simplified by the co-sphere overlap model ${ }^{19-20}$. Various types of interaction between amino acids and sucrose are classified as follows.

Hydrophilic- ionic interaction; interaction between the $\mathrm{OH}$ group of the sucrose and the Zwitter ionic centers of the amino acids. Hydrophilic -Hydrophilic interaction: interaction between the $\mathrm{OH}$ group of the sucrose and the $-\mathrm{NH}_{2}$ group of the amino-acid (glycine/alanine) mediated through Hydrogen bonding. Hydrophobic-Hydrophobic interaction: interaction between the non polar sides group of the sucrose and the non polar group of the amino-acid. Hydrophobic- Hydrophilic interaction: interaction between the $\mathrm{OH}$ group of the sucrose molecules, and the non-polar group of amino-acid.

The interactions of type (1) \& (2) contribute positive transfer volume, while type (3) \& (4) contribute negatively. The introduction of a $\mathrm{CH}_{3}$ group in alanine provides additional tendency of hydrophilic-hydrophobic as well as hydrophobic-hydrophobic interaction. The temperature dependence of limiting apparent molar volume, $\Phi_{\mathrm{v} 0}$ for amino acids in aqueous sucrose solution can be given by following expression ${ }^{17}$.

$$
\Phi_{\mathrm{v} 0}=\mathrm{a}_{0}+\mathrm{a}_{1} \mathrm{~T}+\mathrm{a}_{2} \mathrm{~T}^{2}
$$

The partial molar expansibilities of amino acids in aqueous sucrose were calculated and recorded in Table 4. 
Table 4. $\emptyset_{\mathrm{E} 0}\left(\mathrm{~cm}^{3} \mathrm{~mol}^{-1} \mathrm{~K}^{-1}\right)$ of glycine and $L$-alanine in aqueous sucrose solution at different temperatures $(293.15,303.15$ and $313.15 \mathrm{~K})$

\begin{tabular}{ccccccc}
\hline $\begin{array}{c}\text { Conc. } \mathrm{m} \\
\text { Sucrose }\end{array}$ & $293.15 \mathrm{~K}$ & $303.15 \mathrm{~K}$ & $313.15 \mathrm{~K}$ & $293.15 \mathrm{~K}$ & $303.15 \mathrm{~K}$ & $313.15 \mathrm{~K}$ \\
\hline 0.25 & 0.0863 & 0.0897 & 0.093 & 0.148 & 0.093 & 0.038 \\
0.20 & 0.0851 & 0.0889 & 0.092 & 0.145 & 0.092 & 0.039 \\
0.15 & 0.0835 & 0.0905 & 0.097 & 0.144 & 0.094 & 0.044 \\
0.10 & 0.0835 & 0.0925 & 0.101 & 0.147 & 0.093 & 0.039 \\
0.05 & 0.0835 & 0.0925 & 0.1015 & 0.132 & 0.085 & 0.038 \\
\hline \multicolumn{7}{c}{$\Phi_{\mathrm{E} 0}=\left(\partial \Phi_{\mathrm{v} 0} / \partial \mathrm{T}\right)_{\mathrm{p}=} \mathrm{a}_{1}+2 \mathrm{a}_{2} \mathrm{~T}$}
\end{tabular}

The structure making and breaking capacity of amino acids in aqueous sucrose may be interpreted with the help of Hepler's ${ }^{21}$ reasoning i.e. on the basis of sign of giving expression, it has been assumed that structure making solute have positive and structure breaking solute has negative value.

\section{Viscometric properties}

$$
\left(\partial \Phi_{\mathrm{E} 0} / \partial_{\mathrm{T}}\right)_{\mathrm{p}}=\left(\partial^{2} \Phi_{\mathrm{v} 0} / \partial_{\mathrm{T}}^{2}\right)_{\mathrm{p}=}-\mathrm{a}_{2}
$$

Viscosity data has been analyzed with the help of Jones-Dole ${ }^{22}$ equation using linear relation of $\left[\left(\eta / \eta_{0)-1}\right] / c^{1 / 2}\right.$ with $c^{1 / 2}$ by least square method. The viscosity $A$ and $B$ coefficients ${ }^{23}$ were obtained from the intercepts and slopes and are given in Table 5.

$$
\eta / \eta_{0}=\eta \mathrm{r}=1+\mathrm{A} \mathrm{c}^{1 / 2}+\mathrm{BC}
$$

Table 5. Viscosity B coefficient $\left(\mathrm{m}^{3} \mathrm{~mol}-{ }^{1}\right)$ of glycine and $L$-alanine in aqueous sucrose solution at different temperatures $(293.15,303.15$ and $313.15 \mathrm{~K})$

\begin{tabular}{ccccccc}
\hline $\begin{array}{c}\text { Conc. } \\
\mathrm{m}\end{array}$ & $293.15 \mathrm{~K}$ & $303.15 \mathrm{~K}$ & $313.15 \mathrm{~K}$ & 293.15 & 303.15 & 313.15 \\
\hline 0.25 & 0.1153 & 0.087 & 0.074 & 0.1457 & 0.1471 & 0.158 \\
0.20 & 0.1019 & 0.0815 & 0.066 & 0.132 & 0.139 & 0.143 \\
0.15 & 0.0886 & 0.0639 & 0.0535 & 0.125 & 0.131 & 0.135 \\
0.10 & 0.0699 & 0.0547 & 0.0509 & 0.112 & 0.116 & 0.121 \\
0.05 & 0.503 & 0.0486 & 0.0438 & 0.109 & 0.11 & 0.116 \\
\hline
\end{tabular}

The values of $(\mathrm{dB} / \mathrm{dT})^{24}$ were calculated from the slope of the curve obtained with $B$ - coefficient value against temperatures and recorded in Table 6 . The sign of $(\mathrm{dB} / \mathrm{dT})$ value was found to provide information regarding the structure making and breaking ability of solute in solvent media. In general $(\mathrm{dB} / \mathrm{dT})$ was negative for structure making and positive for structure breaking. These are in identical agreement with the conclusion drawn from Hepler equation.

Table 6. $\mathrm{dB} / \mathrm{dT}$ of glycine and $L$-alanine in aqueous sucrose solution at different temperatures $(293.15,303.15$ and $313.15 \mathrm{~K})$

\begin{tabular}{ccc}
\hline Conc. of sucrose, $\mathrm{m}$ & Glycine & L-Alanine \\
\hline 0.25 & -0.00207 & 0.00061 \\
0.20 & -0.0018 & 0.00055 \\
0.15 & -0.00176 & 0.0005 \\
0.10 & -0.00095 & 0.00045 \\
0.05 & -0.00033 & 0.00035 \\
\hline
\end{tabular}


Determination of the free energy of activation of viscous flow of per mole of solute and solvent at different temperatures to obtained additional information, evaluated by the Erying viscosity relation $^{25-26}$.

$$
\Delta \mathrm{G}=\mathrm{RT} \ln \left(\eta_{0} \mathrm{~V}_{1} / \mathrm{h} \mathrm{N}\right)
$$

Where $\mathrm{h}$ is the Plank constant, $\mathrm{N}$ is the Avogadro number; $\eta$ is the viscosity of the solvent and $\Delta \mathrm{G}$ is the contribution per mole of the solute to the free energy of activation for viscous flow of the solution at infinite dilution, $\mathrm{V}$ is the molar volume $\mathrm{e}^{27}$ of solution which obtained from the relation-

$$
\mathrm{V}=\left(10^{3}+\mathrm{mM}_{2}\right) / \mathrm{d}\left(10^{3} / \mathrm{M}_{1}+\mathrm{m}\right)
$$

Where $\mathrm{M}_{1}$ and $\mathrm{M}_{2}$ are molecular weight for solvent and solute respectively and the other symbol has their usual meanings. The values of free energy of activation for viscous flow for water are $9.31,9.05$ and $8.84 \mathrm{~kJ} \mathrm{~mol}^{-1}$ at $293.15,303.15 \mathrm{~K}$ and $313.15 \mathrm{~K}$ respectively.

The values of $\Delta \mathrm{S}^{28}$ and $\Delta \mathrm{H}$ was calculated by least square method using temperature dependant data of $\Delta \mathrm{G}$. The Values of $\Delta \mathrm{G}$ were found to be positive at all studied temperatures.

Results shows density and viscosity increases with concentration of amino acids and decreases with increasing in temperature. Increasing values of density and viscosity shows that there is moderate attraction with solute and solvent molecules and decreased value with increasing temperature shows decrease in intermolecular forces due to increasing thermal energy of the system.

It is found that value of $\Phi v_{0}$ for all amino acids (Table 1) is Positive and their trend in solute-solvent interaction is in order of glycine $<L$-alanine. This shows that solute solvent interaction increases with increase in number of carbon atoms. Similar conclusion has been reported for glycine in aqueous $\mathrm{NH}_{4} \mathrm{Cl}^{29}, \mathrm{NaCl}-\mathrm{KCl}^{30}$, methanoic acid ${ }^{31}$ and glycerol ${ }^{32}$ solution as $\Phi \mathrm{v}_{0}$ increases with increasing temperature. It can be observed that $\Phi \mathrm{v}_{0}$ increase with temperature showing that the reduction of electrostriction occurs at higher temperature. The $\Phi_{\mathrm{v} 0}$ values are high in comparison to $S_{\mathrm{v}}$ for all concentration range, which suggests the primacy of solute-solvent interaction.

It is found that values of $S_{v}$ are positive for glycine and negative for alanine in aqueous sucrose solution. It suggests that in glycine-sucrose system having more solute-solute interactions in comparison to $L$-alanine -sucrose system.

In glycine-sucrose system negative $\Delta \Phi v_{0 \text { tr }}$ (Table 3 ) decrease with increasing concentration and temperature, suggests that the electrostriction first increase and then decrease with increasing temperature. It brings about decrease in volume of the solvent thereby increasing the strong interaction between sucrose and water. In glycine-sucrose system, hydrophobic interactions are leading at lower concentration, while at higher concentration hydrophilic interactions are leading. This behavior is consistent with the studied of amino acid in tetra-propyl ammonium bromide ${ }^{33} /$ silver sulphate ${ }^{34}$. Opposite ehavior has been reported by $\mathrm{Pal}^{35}$ in higher concentration of sucrose solution.

In alanine-sucrose system it can be accomplish that the positive $\Delta \Phi \mathrm{v}_{0 \text { tr }}$ values (Table 3 ) are decreases constantly with decreasing sucrose concentration at $293.15 \mathrm{~K}$. Its turns negative at $303.15 \mathrm{~K}$ further at $313.15 \mathrm{~K}$ this turn positive. Both positive and negative $\Delta \Phi \mathrm{v}_{0 \text { tr }}$ value observed at all temperatures.

The electrostriction of the neighboring water will be decrease due to charged centers of alanine; this will lead to decrease in reduction of shrinkage. It brings about increase in 
volume of the solvent thereby decreasing the strong interaction between carbohydrate and water. This will lead to positive volume transfer. This is consistent with amino acid in tatrazine ${ }^{36}$ and in glycerol ${ }^{32 .}$ At higher temperature increase in the interaction between $\mathrm{OH}$ group of sucrose and non polar group of the $L$-alanine leads to the disruption of hydration sphere of the charged centre of amino acids. This decreased the positive contribution, or in other words it may be say that there is an increase in electrostriction. In alanine-sucrose system hydrophilic interactions are dominating over hydrophobic interactions at higher concentration. Both negative and positive transfer volume has been reported by $\mathrm{Pal}^{35}$ for $L$-alanine in higher concentration of sucrose solution.

The limiting apparent molar expansibilities $\Phi_{\mathrm{E} 0}$ for alanine in aqueous sucrose showed that value increase with increasing concentration and decrease with increasing temperatures. Its behavior is just like common salt ${ }^{37}$. Positive increase in $\Phi_{\mathrm{E} 0}$ may indicate the presence of caging effect ${ }^{38}$. The obtained negative sign of $\left(\partial^{2} \Phi_{\mathrm{v} 0} / \partial \mathrm{T}^{2}\right)_{\mathrm{p}}$ value has suggests structure breaking nature of alanine in aqueous sucrose solution. The limiting apparent molar expansibilities for glycine in aqueous sucrose at different temperature showed that positive $\Phi_{\mathrm{E} 0}$ value increase with increasing concentration and temperature. The positive sign of $\left(\partial^{2} \Phi_{\mathrm{v} 0} / \partial \mathrm{T}^{2}\right)_{\mathrm{p}}$ value has exhibits structure making nature of glycine in aqueous sucrose solution.

Values of A coefficients are negative for glycine and $L$-alanine in aqueous sucrose at all the investigated temperatures. These results indicate the presence of weak solute-solute interaction.

The value of $B$-coefficient is positive, which point out the existence of ion-solvent interaction. The values of $B$-coefficient for alanine in aqueous sucrose solution are very higher at higher temperature that proves the increase of ion-solvent interaction at higher temperature. The value of $B$-coefficient for glycine (Table 5) is positive and decreases with rise in temperature whereas for alanine it first decreases at $303.15 \mathrm{~K}$ and then increase at higher temperature suggests that solvation first decrease and then increases with increase in temperature.

Positive (dB/dT) (Table 6) value reveals that structure breaking capacity of alanine in aqueous sucrose solution increases with increasing concentration. While negative value of $(\mathrm{dB} / \mathrm{dT})$ indicates structure making aptitude of glycine in aqueous sucrose solution decrease with increasing concentration. These are in identical agreement with the conclusion drawn from Hepler equation as discussed earlier. Such the values of coefficient A and B supports the behaviors of $\Phi \mathrm{v}_{0}$ and $\mathrm{S}_{\mathrm{v}}$ and $\Phi \mathrm{v}_{0 \text { tr }}$ which all suggest solute-solvent interaction predominant over solute-solute interaction.

It is evident from Table 7 in case of glycine / alanine-sucrose system, positive value of $\Delta \mathrm{G}$ decreases with the increase in solute concentration and increases with the rise of temperature. This behavior of $\Delta \mathrm{G}^{39}$ suggests that the positive work is required to create holes for viscous flow and at higher temperature the solute-solvent and solventsolvent interactions weaken due to thermal agitation. The positive value of $\Delta H$ irregularly decreases with the increase of solute composition. This indicates that to overcome the energy barrier, less positive work has to be done. Thus the viscous flow is not favored for all the sucrose molecules in solution systems. This might be due to the fact that the ground state of the binary and ternary systems is more organized than the transition states. 
Table 7. Thermodynamic function $\Delta \mathrm{G}, \Delta \mathrm{H}$ and $\Delta \mathrm{S}$ for glycine in aqueous sucrose solution at different temperatures $(293.15,303.15$ and $313.15 \mathrm{~K})$

\begin{tabular}{|c|c|c|c|c|c|}
\hline $\begin{array}{l}\text { Glycine } \\
\text { mol. }^{-3} \mathrm{~m}\end{array}$ & $\begin{array}{c}\Delta \mathrm{G} \\
\mathrm{J} \mathrm{mol}^{-1}\end{array}$ & $\begin{array}{c}\Delta \mathrm{G} \\
\mathrm{J} \mathrm{mol}^{-1}\end{array}$ & $\begin{array}{c}\Delta \mathrm{G} \\
\mathrm{J} \mathrm{mol}^{-1}\end{array}$ & $\begin{array}{c}\Delta \mathrm{S} \\
\mathrm{J} \mathrm{mol}^{-1} \mathrm{~K}^{-1}\end{array}$ & $\begin{array}{c}\Delta \mathrm{H} \\
\mathrm{J} \mathrm{mol}^{-1} \mathrm{~K}^{-1}\end{array}$ \\
\hline \multicolumn{6}{|c|}{$0.25 \mathrm{~m}$ Sucrose } \\
\hline & $293.15 \mathrm{~K}$ & $303.15 \mathrm{~K}$ & $313.15 \mathrm{~K}$ & & \\
\hline 0.0626 & 32468.69 & 33001.43 & 33658.45 & 59.488 & 15008.96 \\
\hline 0.0939 & 32457.18 & 32986.84 & 33642.07 & 59.244 & 15068.81 \\
\hline 0.1566 & 32423.47 & 32949.82 & 33604.64 & 59.058 & 15089.03 \\
\hline \multicolumn{6}{|c|}{$0.20 \mathrm{~m}$ Sucrose } \\
\hline 0.0626 & 32362.7 & 32920.54 & 33559.92 & 59.860 & 14800.91 \\
\hline 0.0939 & 32348.05 & 32903.25 & 33541.77 & 59.685 & 14837.32 \\
\hline 0.1566 & 32314.96 & 32867.96 & 33505.3 & 59.517 & 14853.37 \\
\hline \multicolumn{6}{|c|}{$0.15 \mathrm{~m}$ Sucrose } \\
\hline 0.0626 & 32254.17 & 32842.27 & 33506.65 & 62.624 & 13883.23 \\
\hline 0.0939 & 32236.9 & 32826.44 & 33486.58 & 62.483 & 13907.98 \\
\hline 0.1566 & 32202.57 & 32787.97 & 33447.74 & 62.258 & 13939.09 \\
\hline \multicolumn{6}{|c|}{$0.10 \mathrm{~m}$ Sucrose } \\
\hline 0.0626 & 32133.17 & 32723.28 & 33420.66 & 64.374 & 13243.98 \\
\hline 0.0939 & 32116.88 & 32705.12 & 33401.3 & 64.22 & 13272.51 \\
\hline 0.1566 & 32080.2 & 32666.4 & 33361.35 & 64.057 & 13283.62 \\
\hline \multicolumn{6}{|c|}{$0.05 \mathrm{~m}$ Sucrose } \\
\hline 0.0626 & 32031.32 & 32736.87 & 33293.38 & 63.103 & 13557.45 \\
\hline 0.0939 & 32013.08 & 32717.29 & 33273.39 & 63.015 & 13564.75 \\
\hline 0.1566 & 31975.44 & 32678.95 & 33233.33 & 62.894 & 13562.76 \\
\hline
\end{tabular}

\section{Conclusion}

It has been concluded that glycine behaves as structure-maker in aqueous sucrose solution. In aqueous sucrose solutions the behavior of alanine shows disruption of water structure at higher concentration and lower temperature region and enhancing of water structure at lower concentration and at higher temperature region. This indicates $L$-alanine behaves both as structure maker and breaker.

\section{References}

1. Galema S A and Hoeiland H, J Phys Chem., 1991, 95(13), 5321-5326.

2. Galema S A, Blandamer M J and Engberts J B F N, J Am Chem Soc., 1990, 112(26), 9665-9666.

3. Banipal P K, Banipal T S, Lark B S and Ahluwalia J C, J Chem Soc Faraday Trans., 1997, 93, 81-87.

4. Banipal P K, Banipal T S, Lark B S and Ahluwalia J C, J Chem Thermodyn, 2000, 32(10), 1409-1432.

5. Morel J-P, Lhermet C and Desrosiers N-M, Canadian J Chem., 1986, 64(5), 996-1001.

6. Metzler D E, The Chemical Reactions of Living Cells, Academic Press, New York, $1977,1$.

7. Kharakoz D P, J Phys Chem., 1991, 95(14), 5634-5642.

8. Kharakoz D P, Biophys Chem., 1989, 34(2), 115-125.

9. Wadi R K and Goyal R K, J Soln Chem., 1992, 21(2), 163-170.

10. Wadi R K and Ramaswami P, J Chem Soc Faraday Trans., 1997, 93, 243-247. 
11. Ali A, Khan S and Nabi F, J Serb Chem Soc., 2007, 72(1), 495-512.

12. Ali A, Sabir S, Nain A K, Hyder S, Ahmad S, Tariq M and Patel R, J Chinese Chem Soc., 2007, 54, 659.

13. Kitchner J A, Findlay's, Practical Physical Chemistry, $8^{\text {th }}$ Edn., Longman, London, 1954, 70.

14. Shoemaker D and Garland C, Experiments in Physical Chemistry, McGraw-Hill, New York, 1967, 131.

15. Panda B B, Dixit G and Behera B, Bull Chem Soc Japan, 1936, 69(2), 301-303.

16. Masson D O, Philos Mag., 1929, 8, 218.

17. Gupta R R and Singh M, J Indian Chem Soc., 2008, 85, 176-181.

18. Zhuo K, Lfu Q, WangY, Yaping Wang, Qiuhe Ren and Jianji Wang Jianji Wang, $J$ Chem Eng Data, 2006, 51(3), 919-927.

19. Gurney R W, Ionic Processes in Solution, McGraw-Hill New York, 1953, 3.

20. Friedman H and Krishnan L, J Solution Chem., 1973, 2(1), 37-51.

21. Hepler L, Canadian J Chem., 1969, 47(24), 4613-4617.

22. Jones G and Dole M, J Am Chem Soc., 1929, 51(10), 2950-2964.

23. Jenkins B, Donald H and Marcus Y, Chem Rev., 1995, 95(8), 2695-2724.

24. Ali A, Soghra Hyder, Saba Sabirm, Anil Kumar Nain and Chand D, J Chem Thermodyn., 2006, 38(2), 136-143.

25. Feakins D, Canning F M, Waghorne W E and Lawrence K G, J Chem Soc Faraday Trans., 1993, 89, 3381-3389.

26. Glasstone S, Laidler K J and Eyring H, The Theory of Rate Processes, McGraw- Hill, New York, 1941.

27. Habeeb S A, J Al-Nahrain Univ., 2011, 14(4), 45-49.

28. Uddin F and Saeed R, Acta Cintifica, 2001, 52(3), 186-191.

29. Natrajan M, Wadi R K and Gaur H C, J Chem Eng Data, 1990, 35(1), 87-93.

30. Ogawa T, Mizutani K and Yasuda M, Bull Chem Soc Japan, 1984, 57(8), 2064-2068.

31. Roy M N, Ekka D and Dewan R, Acta Chim Slov., 2011, 58(4), 792-796.

32. Banipal T S, Gagandeep Singh and Lark B S, J Soln Chem., 2001, 30(7), 657-670.

33. Ali A, Khan S, Hyder S and Tariq M, J Chem Thermodyn., 2007, 39(4), 613-620.

34. Sinha B, Roy P K and Roy M N, Acta Chim Slov., 2010, 57(3), 651-659.

35. Pal A, Ramniwas and Chauhan N, Indian J Chem., 2010, 49A, 1309-1317.

36. Ali A, Khan S, Hyder S and Tariq M, J Chem Thermodyn, 2007, 39(4), 613-620.

37. Shashi Kant and Kumar K, J Indian Chem Soc., 2008, 85, 1093-1101.

38. Millero F J, Structure and Transport process in water and aqueous solution, R A. Horne, Wiley Interscience, New York, 1971.

39. Dey P, Muhamman A Motin and Entaazul M Huque, Monatshefte Fur Chemie., 2003, 134, 797-809. 